\title{
Editorial
}

\section{Innovative Design of Mechanisms}

\section{Jing-Shan Zhao*}

\section{Department of Precision Instruments and Mechanology, Tsinghua University, Beijing 100084, P. R. China}

This special issue is aimed to provide a forum for publication of original research and developments in innovative design of mechanisms. Innovative design plays a very important role in mechanical engineering. The novel mechanism concepts and new synthesis methods have been extensively explored in the past decades, considerably contributing to improvement of mechanical products, such as the advanced vehicles, new spatial manipulators and industrial robots. One of the primary trends of today and tomorrow's mechanical engineering is the development of advanced products with new-configuration and singularity-free workspace, which consequently poses significant challenges on mechanism synthesis. Therefore, this special issue for the innovative design of mechanisms, which may either improve the system

*Address correspondence to this author at the Department of Precision Instruments and Mechanology, Tsinghua University, Beijing 100084, P. R. China; Tel: 86-10-62788308; Fax: 86-10-62788308;

E-mail: jingshanzhao@mail.tsinghua.edu.cn dynamic performance or provide large workspace. The selected five papers in this journal special issue focus on novel mechanism concepts design, workspace computation, the engineering applications of on-road vehicles, deployable mechanism theory and application.

I would like to express grateful thanks to Dr. Duanling Li from Beijing Post and Telecommunication University, Dr. Xiuli Zhang from Beijing Jiaotong University and Dr. Guowu Wei from King's College London and my colleagues in Tsinghua university for having enthusiastically in advertising and reviewing papers for this special issue. I should also thank the authors, who have contributed with very interesting papers in several subjects, covering many fields of innovative design of mechanisms. I acknowledge them for their cooperation in revising papers. I would like to thank the Publisher and Editorial staff of this journal for accepting and helping the publication of this special issue.

(C) Jing-Shan Zhao; Licensee Bentham Open .

This is an open access article licensed under the terms of the Creative Commons Attribution Non-Commercial License (http://creativecommons.org/licenses/by$\mathrm{nc} / 3.0 /$ ), which permits unrestricted, non-commercial use, distribution and reproduction in any medium, provided the work is properly cited. 